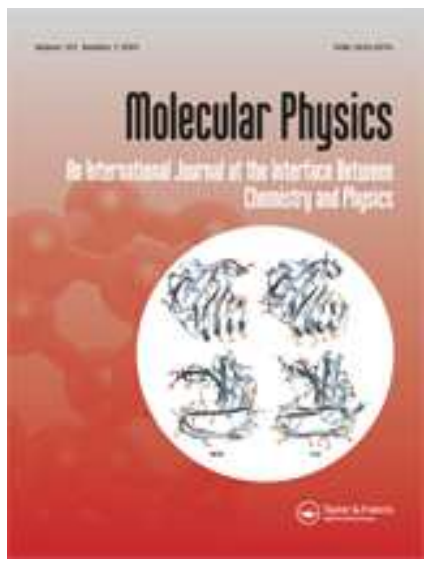

\title{
Ab initio pair potential energy curve for the argon atom pair and thermophysical properties of the dilute argon gas. \\ I. Argon-argon interatomic potential and rovibrational spectra
}

\begin{tabular}{|c|c|}
\hline Journal: & Molecular Physics \\
\hline Manuscript ID: & TMPH-2009-0212 \\
\hline Manuscript Type: & Full Paper \\
\hline $\begin{array}{r}\text { Date Submitted by the } \\
\text { Author: }\end{array}$ & 15-Jul-2009 \\
\hline Complete List of Authors: & $\begin{array}{l}\text { Jäger, Benjamin; Universität Rostock, Institut für Chemie } \\
\text { Hellmann, Robert; Universität Rostock, Institut für Chemie; } \\
\text { Universität Rostock, Institut für Chemie } \\
\text { Bich, Eckard; Universität Rostock, Institut für Chemie } \\
\text { Vogel, Eckhard; Universität Rostock, Institut für Chemie; } \\
\text { Universität Rostock, Institut für Chemie }\end{array}$ \\
\hline Keywords: & ab initio pair potential, rovibrational spectra \\
\hline \multicolumn{2}{|c|}{$\begin{array}{l}\text { Note: The following files were submitted by the author for peer review, but cannot be converted } \\
\text { to PDF. You must view these files (e.g. movies) online. }\end{array}$} \\
\hline Argon1-molphys.tex & \\
\hline
\end{tabular}




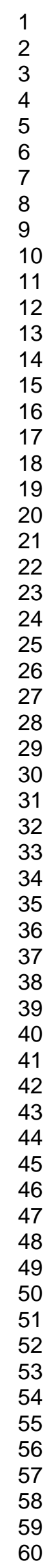

\section{$\$$ Manuscript Central}

URL: http://mc.manuscriptcentral.com/tandf/tmph 
Molecular Physics, Vol. 00, No. 00, DD Month 200x, 1-12

\title{
$A b$ initio pair potential energy curve for the argon atom pair and thermophysical properties of the dilute argon gas. \\ I. Argon-argon interatomic potential and rovibrational spectra
}

\author{
Benjamin Jäger, Robert Hellmann, Eckard Bich, and Eckhard Vogel* \\ Institut für Chemie, Universität Rostock, Albert-Einstein-Straße 3a, D-18059 Rostock, \\ Germany \\ (Received 00 Month 200x; in final form 00 Month 200x)
}

\begin{abstract}
An argon-argon interatomic potential energy curve was derived from quantum-mechanical $a b$ initio calculations using basis sets of up to d-aug-cc-pV $(6+\mathrm{d}) \mathrm{Z}$ quality supplemented with bond functions and $a b$ initio methods up to $\operatorname{CCSDT}(\mathrm{Q})$. In addition, corrections for relativistic effects were determined. An analytical potential function was fitted to the $a b$ initio values and utilized to compute the rovibrational spectrum. The quality of the interatomic potential function was tested by comparison of the calculated spectrum with experimental ones and those derived from other potentials of the literature. In a following paper the new interatomic potential is used to determine selected thermophysical properties of argon by means of quantum-statistical mechanics and the corresponding kinetic theory considering two-body and three-body interactions.

Keywords: argon ab initio pair potential; argon analytical potential function; rovibrational spectra.
\end{abstract}

\section{Introduction}

The properties of rare gases are of considerable interest for both the development of modeling techniques and as standard values for experiments. Moreover, argon is of special interest in the field of metrology. For the determination of thermophysical fluid properties the knowledge of the potential energy curve between two rare gas atoms is required. Recently, we demonstrated that for helium and neon highly accurate pair potentials can be calculated $a b$ initio, i.e. purely from theory $[1,2]$. The resulting thermophysical properties $[3,4]$ were found to be more accurate than experimental values and can therefore be utilized for calibration of high precision measuring instruments. Since argon is one of the pioneer substances of molecular modeling and a low price alternative for calibration issues, a pair potential of high quality is needed.

*Corresponding author. Email: eckhard.vogel@uni-rostock.de 
Aziz and coworkers [5-7] as well as Boyes [8] followed the standard approach and fitted analytical potential functions to experimental data such as transport properties, pressure virial coefficients, acoustic virial coefficients and rovibronic spectra. These empirical potentials allow the description of low density argon with high accuracy for certain temperature ranges. However, for extreme temperature regions their reliability is questionable because of the lack of high precision experimental values.

The computational feasibility of highly correlated $a b$ initio methods such as the Møller-Plesset perturbation theory (MP2,MP3,MP4) and the coupled-cluster approach (CC) opened the door to calculations of potential curves entirely from theory. Utilizing MP4 Chałasiński et al. [9] calculated the potential energy between two argon atoms underestimating the well depth compared to the Boyes potential [8] by about 25\%. A reduced error of $13 \%$ resulted from computations with the interacting correlated fragments approach (ICF) carried out by McLean et al. [10]. By the introduction of the coupled-cluster approach with full iterative single and double excitations and non-iterative perturbational treatment of triple excitations $(\mathrm{CCSD}(\mathrm{T})[11])$ in combination with the new augmented correlation-consistent basis sets (aug-cc-pVXZ) by Woon and Dunning [12] a considerable improvement in accuracy was achieved. The well depth of the potential calculated by Woon [13] at the frozen-core CCSD(T) level using basis sets up to d-aug-cc-pVQZ and complete basis set (CBS) extrapolation deviated only by $6 \%$ from the empirical value. Van Mourik et al. [14] decreased the error by another $3 \%$ utilizing basis sets up to d-augcc-pV6Z, CBS extrapolation and corrections for the effects of core-core and corevalence correlation. Additional midbond functions (3s3p2d1f1g) and the d-aug-ccpV5Z basis set were used by Fernandez and Koch [15] to enhance the convergence of the correlation energy, so that the well depth of their potential was only about $2 \%$ too small. Comparable results were obtained by Cybulski and Toczyłowski [16] with the aug-cc-pV5Z basis set and midbond functions (3s3p2d2f1g).

A similar approach was used by Slavíček et al. [17], who calculated the interaction energies with the aug-cc-pV6Z basis set and midbond functions (3s $3 \mathrm{p} 2 \mathrm{~d} 2 \mathrm{f} 1 \mathrm{~g}$ ) at the frozen-core CCSD(T) level of theory. They also accounted for the effects of core-core and core-valence correlation, that increased the well depth considerably. However, they overestimated this correction by using an aug-cc-pV5Z basis set with midbond functions instead of more suitable aug-cc-pCVXZ or aug-ccpwCVXZ basis sets by Peterson and Dunning [18]. Slavíček et al. were the first to study the impact of higher CC terms on the Ar-Ar interaction energy, especially the difference between the CCSDT [19] (with full iterative triple excitations) and $\operatorname{CCSD}(\mathrm{T})$ levels. Since this term was positive $(0.9 \mathrm{~K}$ at $R=0.38 \mathrm{~nm})$, i.e. decreasing the well depth of the potential, it was neglected in the final potential energy curve. The obtained pair potential was characterized by a well depth $\varepsilon / k_{\mathrm{B}}$ 


\section{Computation of the Ar-Ar pair potential}

Following the general pathway described for neon in [2] we performed quantum chemical calculations on the argon atom pair for 38 different Ar-Ar distances between $R=0.18 \mathrm{~nm}$ and $R=1.50 \mathrm{~nm}$. The interaction energies were determined by the supermolecular approach including a full counterpoise correction [21] given by:

$$
V(R)=\Delta E_{\mathrm{Ar}-\operatorname{Ar}}(R)=E_{\mathrm{Ar}-\operatorname{Ar}}(R)-2 E_{\mathrm{Ar}-\mathrm{Q}}(R),
$$

where $E_{\mathrm{Ar}-\mathrm{Q}}(R)$ is the energy of an argon monomer with a complete dimer basis, i.e. with a ghost basis set at the distance $R$.

Starting at the $\operatorname{CCSD}(\mathrm{T})$ level of theory in the frozen-core approximation we computed the energies utilizing the d-aug-cc-pV $(5+d) \mathrm{Z}$ and d-aug-cc-pV $(6+d) \mathrm{Z}$ basis sets augmented by a set of midbond functions (4s4p3d3f2g) located at the center between the two atoms. The exponents of the bond functions are: $s p: 0.06$, $0.18,0.54,1.62 ; d f: 0.15,0.45,1.35 ; g: 0.3,0.9$. Dunning et al. proposed the cc$\mathrm{pV}(\mathrm{X}+\mathrm{d}) \mathrm{Z}$ series of basis sets [22] for elements of the third row by introducing an additional set of d-functions to the cc-pVXZ basis sets in order to improve the convergence of the atomic SCF-energies towards the CBS limit. We observed, that this improved behavior holds also for the SCF-part of the interaction energies. This is illustrated in Figure 1, which shows interaction energies calculated for the d-augcc-pV $(X+\mathrm{d}) \mathrm{Z}+(4 \mathrm{~s} 4 \mathrm{p} 3 \mathrm{~d} 3 \mathrm{f} 2 \mathrm{~g})$ (as from now abbreviated as daV $X \mathrm{dZ}+(44332))$ and the d-aug-cc-pVXZ (daVXZ+(44332)) basis sets for $X=3-6$ at $R=0.38 \mathrm{~nm}$.

The CBS-extrapolated values of the correlation part of the interaction energy were obtained by using the results from the $\operatorname{CCSD}(\mathrm{T})$ calculations with the daVXdZ+(44332) basis sets $(X=5,6)$ applying the basis set extrapolation for- 


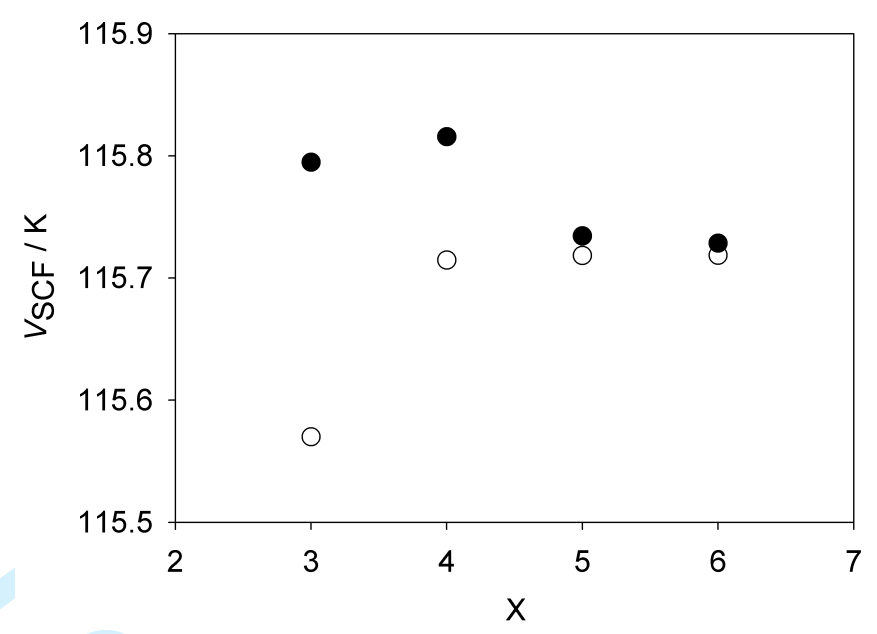

Figure 1. Dependence of the SCF-part of the interaction energy on the basis set type and size at $R=0.38 \mathrm{~nm}$. $\circ$ - represent the results for the daVXdZ+(44332) basis set, $\bullet$ - correspond to the daVXZ+(44332) values.

mula proposed by Halkier et al. [23]:

$$
V_{\mathrm{CCSD}(\mathrm{T}) \text { corr }}^{\mathrm{daVXdZ}}=V_{\mathrm{CCSD}(\mathrm{T}) \text { corr }}^{\mathrm{CBS}}+\alpha X^{-3}
$$

With the daV6dZ+(44332) basis set the SCF interaction energies were found to be converged so that these results were not extrapolated. It is highly satisfactory that our final estimate for the $\operatorname{CCSD}(\mathrm{T})$ energy of $-140.184 \mathrm{~K}$ at $R=0.38 \mathrm{~nm}$ is almost identical to the value obtained by Patkowski et al. [20] $(-140.182 \mathrm{~K}$ at $R=0.38 \mathrm{~nm}$ ), although the basis sets are different.

Crucial improvement of the potential energy curve was achieved by adding several corrections to the interaction energy, namely corrections for the impact of missing core-core and core-valence correlation, for relativistic effects and for the neglect of higher CC terms:

$$
V=V_{\mathrm{CCSD}(\mathrm{T})}^{\mathrm{CBS}}+\Delta V_{\text {core }}+\Delta V_{\mathrm{rel}}+\Delta V_{\mathrm{T}-(\mathrm{T})}+\Delta V_{(\mathrm{Q})}
$$

Calculating the differences between the interaction energies with and without frozen-core approximation the influence of core-core and core-valence electron correlation was accounted for. Van Mourik et al. [14] used the dawCVXZ series of basis sets $(X=\mathrm{D}, \mathrm{T}, \mathrm{Q})[18]$ and obtained the following results for the core corrections: $-0.85 \mathrm{~K}$ at $R=0.405 \mathrm{~nm}$ for $\mathrm{DZ},-1.07 \mathrm{~K}$ at $R=0.386 \mathrm{~nm}$ for $\mathrm{TZ}$ and $-1.13 \mathrm{~K}$ at $R=0.381 \mathrm{~nm}$ for QZ. Furthermore, they extrapolated the correction to the CBS limit $\left(\Delta V_{\text {core }}=-1.14 \mathrm{~K}\right.$ at the minimum of the potential). However, Slavíček et al. and Patkowski et al. respectively utilized core corrections computed with an aV5Z+(33221) basis set, what is certainly not appropriate due to the construction of this basis set for frozen-core calculations. Their value of $-2.2 \mathrm{~K}$ at $R=0.38 \mathrm{~nm}$ 
overestimates the effect substantially. Hence, we used the awCV5Z basis set [18] and obtained a value for the core correction of $-1.07 \mathrm{~K}$ at $R=0.38 \mathrm{~nm}$. Considering the different interatomic separations and basis sets this result is quite close to the data of Van Mourik et al. Generally, $\Delta V_{\text {core }}$ was found to be increasingly important in the repulsive region $(-650 \mathrm{~K}$ at $R=0.18 \mathrm{~nm})$.

At the same all-electron CCSD(T)/awCV5Z level the scalar relativistic effects were calculated by means of the Cowan-Griffin approximation [24]. The resulting correction to the interaction energy $\Delta V_{\text {rel }}$ is negativ for all distances and regarding its size comparable to the core correction. Faas et al. [25] estimated the relativistic effect on the well depth to be about $-1.0 \mathrm{~K}$ using their so-called scaled-ZORA MP2 approach. Taking into account the different Ar-Ar separations and the unequal level of theory, i.e. MP2 instead of $\operatorname{CCSD}(\mathrm{T})$, this value is very close to our results $(-1.05 \mathrm{~K}$ at $R=0.37 \mathrm{~nm}$ and $-0.75 \mathrm{~K}$ at $R=0.38 \mathrm{~nm})$.

The differences in the interaction energies between the CCSDT method and the more approximative $\operatorname{CCSD}(\mathrm{T})$ approach were computed at the frozen-core level utilizing a daVQZ+(3321) basis set with the following exponents of the bond functions: $s p: 0.1,0.3,0.9 ; d: 0.25,0.75 ; f: 0.45$. Contrary to the results for neon [2] $\Delta V_{\mathrm{T}-(\mathrm{T})}$ is positive at all distances. Our values are considerably larger than the ones by Slavíček et al. [17] calculated with an aVTZ+(332) basis set (e.g. 1.49 K vs. $0.86 \mathrm{~K}$ at $R=0.38 \mathrm{~nm}$ ).

Moreover, the impact of a perturbational treatment of quadruple excitations on the interaction energy $\Delta V_{(\mathrm{Q})}$ was investigated using the CCSDT $(\mathrm{Q})$ method $[26,27]$ by calculating the differences between the $\operatorname{CSDT}(\mathrm{Q})$ and the CCSDT levels with the aVTZ+(3321) basis set. We surprisingly found this effect to be $-2.0 \mathrm{~K}$ near the equilibrium distance $(R=0.38 \mathrm{~nm})$, what is about one order of magnitude larger than for neon [2]. Hence, this effect is essentially needed to bring the $a b$ initio pair potentials for argon into agreement with the empirical ones. Because of numerical inaccuracies for some larger values of $R$ the results for distances between $R=0.54 \mathrm{~nm}$ and $R=0.70 \mathrm{~nm}$ had to be smoothed with a polynomial fitted to the ratio of $\Delta V_{(\mathrm{Q})}$ and $V_{\mathrm{CCSD}(\mathrm{T}) \text { corr }}^{\mathrm{daV} 6 \mathrm{dZ}}$. For $R=0.38 \mathrm{~nm}$ we were also able to test the error in using the perturbational instead of the full iterative treatment of the quadruple excitations (CCSDTQ [28]) in analogy to $\Delta V_{\mathrm{T}-(\mathrm{T})}$. This difference was, at least with an aVDZ+(3321) basis set, only $0.10 \mathrm{~K}$. Taking into consideration the enormous computational effort for the CCSDTQ method this effect was neglected.

All CCSD $(\mathrm{T})$ and CCSDT calculations were performed with the Mainz-AustinBudapest version of ACES II [29]. Utilizing the general CC code MRCC of Kállay [30] the computations at the $\operatorname{CCSDT}(\mathrm{Q})$ and CCSDTQ level of theory were realized. The results of all ab initio calculations are given in Tables 1 and 2.

Eventually, the parameters of a modified Tang-Toennies potential function [31] 


\section{Rovibronic spectra of the argon dimer}

Since the comparison of calculated and experimental rovibronic spectra is a very stringent test of any pair potential we calculated the energy differences for the rovibrational transitions of the electronic ground state of the ${ }^{40} \mathrm{Ar}-{ }^{40} \mathrm{Ar}$ dimer with the program LEVEL 7.7 by Le Roy [34]. Beside our results Tables 4 and 5 include the values derived from measurements by Coulborn and Douglas [35] and Herman et al. [36] as well as those calculated from several empirical and ab initio potential functions $[7,8,15,17,20]$. Generally, seven bound vibrational levels were found for all pair potentials. Douglas and Colborn as well as Herman et al. observed six bound levels, whereas the latter group suggested that there may be altogether seven or eight.

The characteristic parameters of the spectra shown in Table 4 demonstrate that the potential of this work is of significantly increased quality compared with the latest $a b$ initio potentials in the literature. The potential well depth is less than $0.1 \%$ smaller than the values from the empirical reference potentials $[7,8]$. One has to consider that the results of Slavíček et al. [17] and Patkowski et al. [20] would have been even worse if they had included the appropriate core correction and the estimates of $\Delta V_{\mathrm{T}-(\mathrm{T})}$ by Slavíček et al. The values for the older potential by Cybulski and Toczyłowski [16] deviate much more from the experimental 


\section{Summary and conclusions}

Utilizing basis sets of up to d-aug-cc-pV $(6+d) Z$ quality with bond functions the interaction energies for the argon atom pair were computed for various interatomic separations at the $\operatorname{CCSD}(\mathrm{T})$ level. Furthermore, corrections for core-core and core-valence correlation, for scalar relativistic effects and for higher-order coupledcluster excitations up to $\operatorname{CCSDT}(\mathrm{Q})$ were calculated. It was found that all these effects are of comparable magnitude. Hence, all of them have to be included for highly accurate $a b$ initio potential energy curves of the argon atom pair.

The parameters of an analytical potential function were fitted to the $a b$ initio values. Eventually, the characteristic rovibrational properties of the ${ }^{40} \mathrm{Ar}-{ }^{40} \mathrm{Ar}$ dimer in the electronic ground state were determined. These results were compared both with values calculated for other potential energy curves from the literature and with highly accurate experimental data. It was found that the new potential is in close agreement with the empirical potentials by Aziz and Boyes $[7,8]$ and shows considerable improvement compared to older $a b$ initio potentials. Since comparison with rovibrational data mainly represents a test of the potential well, we intent to 
show computational results for transport properties of the dilute argon gas, which are essentially dependent on the repulsive part of the potential, in the second paper of this series [37]. Furthermore, this paper will include comparison of calculated and experimentally determined second and third pressure virial coefficients as well as second acoustic and dielectric virial coefficients.

\section{References}

[1] R. Hellmann, E. Bich, and E. Vogel, Mol. Phys., 105, 3013 (2007).

[2] R. Hellmann, E. Bich, and E. Vogel, Mol. Phys., 106, 133 (2008).

[3] E. Bich, R. Hellmann, and E. Vogel, Mol. Phys., 105, 3035 (2007).

[4] E. Bich, R. Hellmann, and E. Vogel, Mol. Phys., 106, 813 (2008).

[5] R. A. Aziz and M. J. Slaman, Mol. Phys., 58, 679 (1986).

[6] R. A. Aziz and M. J. Slaman, J. Chem. Phys., 92, 1030 (1990).

[7] R. A. Aziz, J. Chem. Phys., 99, 4518 (1993).

[8] S. J. Boyes, Chem. Phys. Lett., 221, 467 (1994).

[9] G. Chałasiński, D. J. Funk, J. Simons, and W. H. Breckenridge, J. Chem. Phys., 87, 3569 (1987).

[10] A. D. McLean, B. Liu, and J. A. Barker, J. Chem. Phys., 89, 6339 (1988).

[11] K. Raghavachari, G. W. Trucks, J. A. Pople, and M. Head-Gordon, Chem. Phys. Lett., 157, 479 (1989).

[12] D. Woon, T. H. Dunning Jr., J. Chem. Phys., 98, 1358 (1993).

[13] D. Woon, J. Chem. Phys., 100, 2838 (1994).

[14] T. van Mourik, A. K. Wilson, and T. H. Dunning Jr., Mol. Phys., 96, 529 (1999).

[15] B. Fernández and H. Koch, J. Chem. Phys., 109, 10255 (1998).

[16] S. M. Cybulski and R. R. Toczyłowski, J. Chem. Phys., 111, 10520 (1999).

[17] P. Slavíček, R. Kalus, P. Paška, I. Odvárkovká, P. Hobza, and A. Malijevský, J. Chem. Phys., 119, 2102 (2003).

[18] K. A. Peterson and T. H. Dunning, Jr., J. Chem. Phys., 117, 10548 (2002).

[19] J. Noga and R. J. Bartlett, J. Chem. Phys., 86, 7041 (1987), Erratum J. Chem. Phys., 89, 3401 (1988).

[20] K. Patkowski, G. Murdachaew, C.-M. Fou, and K. Szalewicz, Mol. Phys., 103, 2031 (2005).

[21] S. F. Boys and F. Bernardi, Mol. Phys., 19, 553 (1970).

[22] T. H. Dunning, Jr., K. A. Peterson, and A. K. Wilson, J. Chem. Phys., 114, 9244 (2001).

[23] A. Halkier, T. Helgaker, P. Jørgensen, W. Klopper, H. Koch, J. Olsen, and A. K. Wilson, Chem. Phys. Lett., 286, 243 (1998).

[24] R. D. Cowan and D. C. Griffin, J. Opt. Soc. Am., 66, 1010 (1976).

[25] S. Faas, J. H. van Lenthe, and J. G. Snijders, Mol. Phys., 98, 1467 (2000).

[26] Y. K. Bomble, M. Kállay, J. Gauss, and J. F. Stanton, J. Chem. Phys., 123, 054101 (2005).

[27] M. Kállay and J. Gauss, J. Chem. Phys., 123, 214105 (2005).

[28] N. Oliphant and L. Adamowicz, J. Chem. Phys., 95, 6645 (1991).

[29] J. F. Stanton, J. Gauss, J. D. Watts, P. G. Szalay, and R. J. Bartlett, with contributions from A. A. Auer, D. B. Bernholdt, O. Christiansen, M. E. Harding, M. Heckert, O. Heun, C. Huber, D. Jonsson, J. Jusélius, W. J. Lauderdale, T. Metzroth, C. Michauk, D. R. Price, K. Ruud, F. Schiffmann, A. Tajti, M. E. Varner, J. Vázquez, and the integral packages: MOLECULE (J. Almlöf and P. R. Taylor), PROPS (P. R. Taylor), and ABACUS (T. Helgaker, H. J. Aa. Jensen, P. Jørgensen, and J. Olsen). See, also J. F. Stanton, J. Gauss, J. D. Watts, W. J. Lauderdale, and R. J. Bartlett, Int. J. Quantum Chem. Symp., 26, 879 (1992). Current version see http://www.aces2.de.

[30] MRCC, a string-based general coupled cluster program suite written by M. Kállay. See also M. Kállay and P. R. Surján, J. Chem. Phys., 115, 2945 (2001) as well as: http://www.mrcc.hu.

[31] K. T. Tang and J. P. Toennies, J. Chem. Phys., 80, 3726 (1984).

[32] A. Kumar and W. J. Meath, Mol. Phys., 54, 823 (1985).

[33] A. J. Thakkar, H. Hettema, and P. E. S. Wormer, J. Chem. Phys., 97, 3252 (1992).

[34] R. J. Le Roy, Level 7.7: A Computer Program for Solving the Radial Schrödinger Equation for Bound and Quasibound Levels, University of Waterloo, Chemical Physics Research Report No. CP-661, Waterloo, Ontario, Canada.

[35] E. A. Colbourn and A. E. Douglas, J. Chem. Phys., 65, 1741 (1976). 


\section{Molecular Physics}

[36] P. R. Herman, P. E. LaRocque, and B. P. Stoicheff, J. Chem. Phys., 89, 4535 (1988).

[37] E. Bich, B. Jäger, and E. Vogel, in preparation. 


\section{Page 11 of 15 \\ Molecular Physics}

10

Table 1. Ar-Ar SCF and CCSD(T) interaction energies for the daV5dZ+(44332) and daV6dZ+(44332) basis sets and the extrapolated $\operatorname{CCSD}(\mathrm{T})$ values. All energies are in Kelvin.

\begin{tabular}{|c|c|c|c|c|c|}
\hline \multirow[t]{2}{*}{$R / \mathrm{nm}$} & \multicolumn{2}{|c|}{$\mathrm{V}(\mathrm{SCF})$} & \multicolumn{3}{|c|}{$\mathrm{V}(\operatorname{CCSD}(\mathrm{T}))$} \\
\hline & daV5dZ+(44332) & daV6dZ+(44332) & daV5dZ+(44332) & daV6dZ+(44332) & extrapolated \\
\hline 0.18 & 112186.342 & 112141.930 & 100595.611 & 100404.502 & 100202.993 \\
\hline 0.20 & 60087.052 & 60070.816 & 52406.333 & 52299.655 & 52175.420 \\
\hline 0.22 & 31443.934 & 31437.972 & 26313.728 & 26253.267 & 26178.407 \\
\hline 0.24 & 16177.214 & 16175.002 & 12725.839 & 12691.769 & 12648.008 \\
\hline 0.26 & 8211.837 & 8211.055 & 5875.323 & 5856.414 & 5831.515 \\
\hline 0.28 & 4121.835 & 4121.546 & 2531.132 & 2520.846 & 2507.116 \\
\hline 0.30 & 2048.765 & 2048.645 & 959.954 & 954.535 & 947.256 \\
\hline 0.31 & 1439.643 & 1439.570 & 536.960 & 533.091 & 527.876 \\
\hline 0.32 & 1009.558 & 1009.517 & 260.069 & 257.347 & 253.663 \\
\hline 0.33 & 706.597 & 706.578 & 83.299 & 81.414 & 78.851 \\
\hline 0.34 & 493.657 & 493.649 & -25.614 & -26.893 & -28.639 \\
\hline 0.35 & 344.301 & 344.298 & -89.143 & -89.988 & -91.146 \\
\hline 0.36 & 239.746 & 239.746 & -122.823 & -123.361 & -124.099 \\
\hline 0.37 & 166.689 & 166.689 & -137.295 & -137.617 & -138.060 \\
\hline 0.38 & 115.728 & 115.729 & -139.772 & -139.945 & -140.184 \\
\hline 0.39 & 80.239 & 80.239 & -135.080 & -135.156 & -135.259 \\
\hline 0.40 & 55.562 & 55.562 & -126.407 & -126.419 & -126.437 \\
\hline 0.41 & 38.428 & 38.428 & -115.810 & -115.785 & -115.751 \\
\hline 0.42 & 26.547 & 26.547 & -104.589 & -104.541 & -104.475 \\
\hline 0.43 & 18.319 & 18.320 & -93.531 & -93.468 & -93.381 \\
\hline 0.44 & 12.628 & 12.629 & -83.083 & -83.009 & -82.909 \\
\hline 0.45 & 8.696 & 8.697 & -73.474 & -73.394 & -73.285 \\
\hline 0.46 & 5.983 & 5.984 & -64.794 & -64.711 & -64.599 \\
\hline 0.48 & 2.824 & 2.826 & -50.196 & -50.122 & -50.022 \\
\hline 0.50 & 1.328 & 1.330 & -38.894 & -38.837 & -38.762 \\
\hline 0.52 & 0.622 & 0.624 & -30.264 & -30.224 & -30.172 \\
\hline 0.54 & 0.290 & 0.292 & -23.705 & -23.676 & -23.639 \\
\hline 0.56 & 0.134 & 0.136 & -18.710 & -18.689 & -18.662 \\
\hline 0.59 & 0.042 & 0.043 & -13.321 & -13.308 & -13.293 \\
\hline 0.62 & 0.013 & 0.014 & -9.656 & -9.649 & -9.642 \\
\hline 0.65 & 0.004 & 0.004 & -7.119 & -7.117 & -7.114 \\
\hline 0.70 & 0.000 & 0.001 & -4.432 & -4.432 & -4.434 \\
\hline 0.75 & 0.000 & 0.000 & -2.863 & -2.864 & -2.867 \\
\hline 0.80 & 0.000 & 0.000 & -1.908 & -1.910 & -1.912 \\
\hline 0.90 & 0.000 & 0.000 & -0.917 & -0.918 & -0.919 \\
\hline 1.00 & 0.000 & 0.000 & -0.478 & -0.479 & -0.479 \\
\hline 1.20 & 0.000 & 0.000 & -0.157 & -0.157 & -0.157 \\
\hline 1.50 & 0.000 & 0.000 & -0.040 & -0.040 & -0.040 \\
\hline
\end{tabular}


Table 2. Corrections to the extrapolated $\operatorname{CCSD}(\mathrm{T})$ interaction energies and the final potential values. All energies are in Kelvin.

\begin{tabular}{|c|c|c|c|c|c|}
\hline$R / \mathrm{nm}$ & $\begin{array}{c}\Delta V_{\text {core }} \\
\text { awCV } 5 Z\end{array}$ & $\begin{array}{c}\Delta V_{\text {rel }} \\
\text { awCV } 5 \mathrm{Z}\end{array}$ & $\begin{array}{c}\Delta V_{\mathrm{T}-(\mathrm{T})} \\
\mathrm{daVQZ}+(3321)\end{array}$ & $\begin{array}{c}\Delta V_{(\mathrm{Q})} \\
\mathrm{aVTZ}+(3321)\end{array}$ & $V(R)$ \\
\hline 0.18 & -650.297 & -629.600 & 104.982 & -79.607 & 98948.472 \\
\hline 0.20 & -395.120 & -390.735 & 65.413 & -48.779 & 51406.200 \\
\hline 0.22 & -230.501 & -221.294 & 41.590 & -31.866 & 25736.338 \\
\hline 0.24 & -130.109 & -118.251 & 26.678 & -21.706 & 12404.620 \\
\hline 0.26 & -71.418 & -60.662 & 17.198 & -15.205 & 5701.427 \\
\hline 0.28 & -38.215 & -30.183 & 11.131 & -10.826 & 2439.023 \\
\hline 0.30 & -19.942 & -14.673 & 7.248 & -7.754 & 912.136 \\
\hline 0.31 & -14.266 & -10.161 & 5.869 & -6.563 & 502.756 \\
\hline 0.32 & -10.135 & -7.011 & 4.766 & -5.559 & 235.724 \\
\hline 0.33 & -7.146 & -4.825 & 3.884 & -4.706 & 66.058 \\
\hline 0.34 & -4.997 & -3.316 & 3.177 & -3.978 & -37.753 \\
\hline 0.35 & -3.462 & -2.278 & 2.610 & -3.367 & -97.643 \\
\hline 0.36 & -2.373 & -1.568 & 2.154 & -2.841 & -128.726 \\
\hline 0.37 & -1.605 & -1.084 & 1.787 & -2.404 & -141.366 \\
\hline 0.38 & -1.068 & -0.754 & 1.490 & -2.030 & -142.546 \\
\hline 0.39 & -0.695 & -0.530 & 1.249 & -1.717 & -136.953 \\
\hline 0.40 & -0.439 & -0.378 & 1.053 & -1.457 & -127.658 \\
\hline 0.41 & -0.266 & -0.274 & 0.893 & -1.232 & -116.630 \\
\hline 0.42 & -0.150 & -0.203 & 0.761 & -1.047 & -105.114 \\
\hline 0.43 & -0.074 & -0.154 & 0.652 & -0.892 & -93.849 \\
\hline 0.44 & -0.025 & -0.120 & 0.562 & -0.760 & -83.251 \\
\hline 0.45 & 0.005 & -0.096 & 0.487 & -0.648 & -73.536 \\
\hline 0.46 & 0.023 & -0.078 & 0.424 & -0.556 & -64.786 \\
\hline 0.48 & 0.037 & -0.056 & 0.325 & -0.412 & -50.128 \\
\hline 0.50 & 0.037 & -0.042 & 0.254 & -0.311 & -38.825 \\
\hline 0.52 & 0.032 & -0.033 & 0.200 & -0.233 & -30.207 \\
\hline 0.54 & 0.026 & -0.027 & 0.160 & -0.180 & -23.660 \\
\hline 0.56 & 0.020 & -0.022 & 0.130 & -0.140 & -18.674 \\
\hline 0.59 & 0.014 & -0.017 & 0.096 & -0.098 & -13.298 \\
\hline 0.62 & 0.010 & -0.013 & 0.072 & -0.070 & -9.643 \\
\hline 0.65 & 0.007 & -0.010 & 0.055 & -0.051 & -7.113 \\
\hline 0.70 & 0.004 & -0.007 & 0.036 & -0.031 & -4.432 \\
\hline 0.75 & 0.002 & -0.004 & 0.024 & -0.020 & -2.865 \\
\hline 0.80 & 0.001 & -0.003 & 0.016 & -0.013 & -1.911 \\
\hline 0.90 & 0.001 & -0.002 & 0.008 & -0.006 & -0.918 \\
\hline 1.00 & 0.000 & -0.001 & 0.004 & -0.003 & -0.479 \\
\hline 1.20 & 0.000 & 0.000 & 0.001 & -0.001 & -0.156 \\
\hline 1.50 & 0.000 & 0.000 & 0.000 & 0.000 & -0.040 \\
\hline
\end{tabular}

10

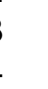

14
5
16

15

(2)

.

(

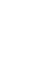

(2)

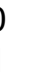

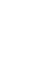

7

9

.

(2)

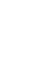


12

Table 3. Potential parameters

Table 4. Equilibrium internuclear distance $R_{\varepsilon}$, dissociation energy $D_{\mathrm{e}}$, vibrational-ground-state dissociation energy $D_{0}$, and the rotational constant $B_{0}$ of the ${ }^{40} \mathrm{Ar}-{ }^{40} \mathrm{Ar}$ dimer in the electronic ground state.

\begin{tabular}{|c|c|c|c|c|}
\hline $\begin{array}{l}R_{\varepsilon} \\
\mathrm{nm}\end{array}$ & $\begin{array}{c}D_{\mathrm{e}} \\
\mathrm{cm}^{-1}\end{array}$ & $\begin{array}{c}D_{0} \\
\mathrm{~cm}^{-1}\end{array}$ & $\begin{array}{c}B_{0} \\
\mathrm{~cm}^{-1}\end{array}$ & Reference \\
\hline 0.3759 & 99.55 & 84.75 & 0.05778 & 35 \\
\hline 0.3761 & 99.20 & 84.47 & $0.05776 \pm 0.00006$ & 36 \\
\hline 0.3757 & 99.55 & 84.75 & 0.05777 & 7 \\
\hline 0.3764 & 99.54 & 84.74 & $0.05755 \pm 0.00011$ & 8 \\
\hline 0.3778 & 96.99 & 82.38 & 0.05708 & 16 \\
\hline 0.3771 & 98.93 & 84.16 & 0.05745 & 17 \\
\hline 0.3767 & 99.27 & 84.38 & 0.05743 & 20 \\
\hline 0.3762 & 99.48 & 84.64 & 0.05760 & this work \\
\hline
\end{tabular}


Table 5. Observed and calculated vibrational intervals $\Delta G_{\nu+1 / 2}$ in $\mathrm{cm}^{-1}$ for the electronic ground state of ${ }^{40} \mathrm{Ar}_{2}$

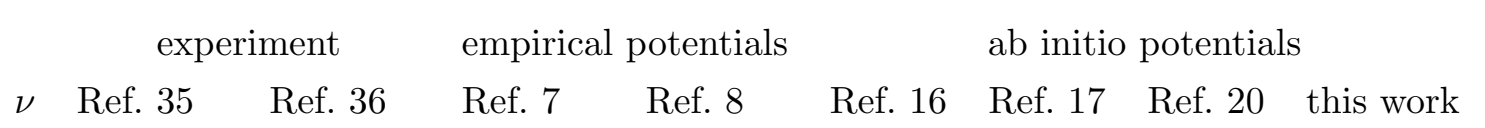

\begin{tabular}{ccc|cc|cccc}
\hline & & & & & & & \\
0 & 25.74 & $25.69 \pm 0.01$ & 25.68 & $25.68 \pm 0.02$ & 25.27 & 25.58 & 25.75 & 25.71 \\
1 & 20.41 & $20.58 \pm 0.02$ & 20.56 & $20.59 \pm 0.02$ & 20.11 & 20.44 & 20.48 & 20.52 \\
2 & 15.60 & $15.58 \pm 0.02$ & 15.58 & $15.57 \pm 0.02$ & 15.15 & 15.46 & 15.44 & 15.52 \\
3 & 10.91 & $10.91 \pm 0.03$ & 10.92 & $10.87 \pm 0.02$ & 10.55 & 10.78 & 10.79 & 10.88 \\
4 & 6.78 & $6.84 \pm 0.07$ & 6.83 & $6.82 \pm 0.07$ & 6.53 & 6.74 & 6.76 & 6.82 \\
\hline
\end{tabular}




\section{Page 15 of 15 \\ Molecular Physics}

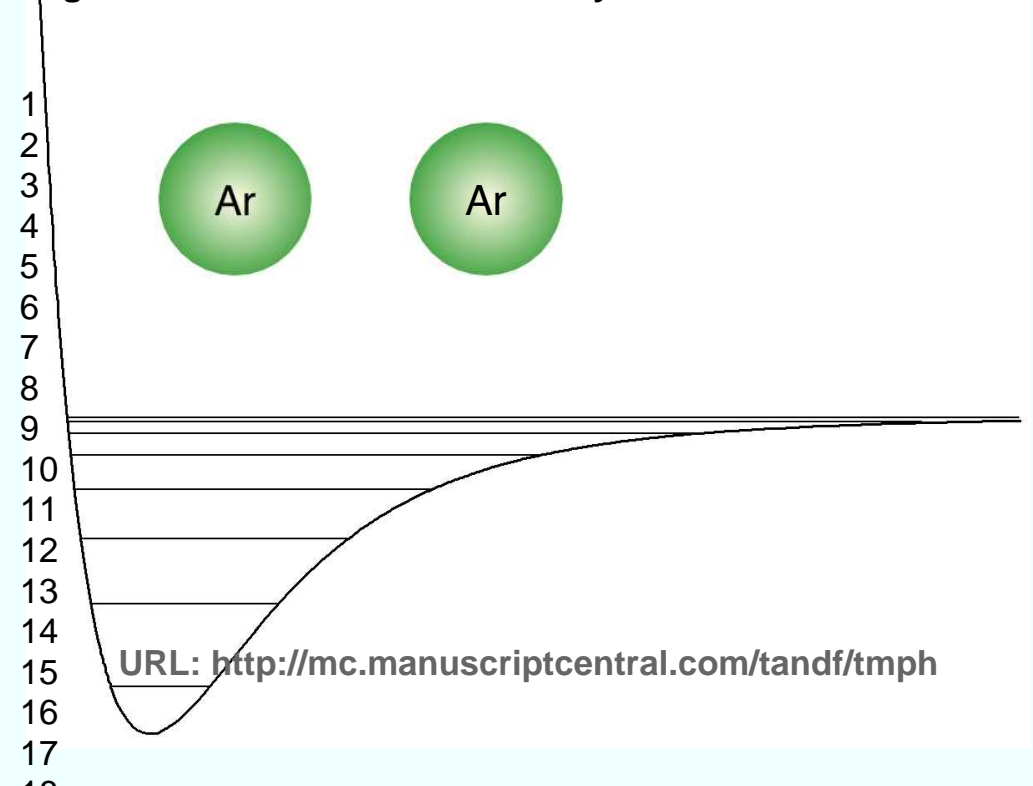


